\title{
Full disclosure about cancer screening
}

Time to change communication from dodgy persuasion to something straightforward

\author{
Gerd Gigerenzer director \\ Harding Center for Risk Literacy and Center for Adaptive Behavior and Cognition, Max Planck Institute for Human Development, Berlin, Germany
}

Communication about cancer screening is dodgy: benefits are overstated and harms downplayed. Several techniques of persuasion are used. These include using the term "prevention" instead of "early detection," thereby wrongly suggesting that screening reduces the odds of getting cancer. Reductions in relative, rather than absolute, risk are reported, which wrongly indicate that benefits are large. ${ }^{1}$ And reporting increases in 5 year survival rates wrongly implies that these correlate with falls in mortality. ${ }^{2}$ Prasad and colleagues put their finger on another misleading practice: claiming that screening "saves lives" despite the lack of proof that overall mortality is decreased. ${ }^{3}$

A fall in cancer specific mortality alone cannot prove that lives are saved - the cause of death may be systematically misclassified or screening and subsequent cancer treatment may increase deaths from other causes, most likely as a consequence of overdiagnosis and overtreatment. ${ }^{34}$ To prove that screening saves lives one needs to find a difference in overall mortality. Yet detecting such a difference, if it exists, with reasonable statistical power in the general population would require studies with millions of participants. Can we get around this dilemma?

Prasad and colleagues propose reporting overall mortality in addition to cancer specific mortality and, if there is no difference in overall mortality, to stop claiming that screening saves lives. I agree but would like to add some additional points to their call for more honesty.

Firstly, reporting cancer specific and overall mortality is essential because not only do patients lack an understanding of what constitutes evidence for "saving lives," but many doctors do too. In a US sample, $47 \%$ of 412 physicians wrongly thought that the detection of more cancers in screened than in unscreened populations proved that screening saves lives. And 76\% wrongly thought that if people with screen detected cancers had better 5 year survival rates than those with symptom detected cancers, then screening saved lives. ${ }^{5}$ Given such widespread confusion, it can be helpful to report both cancer specific mortality and overall mortality.

Secondly, overall cancer mortality should also be reported, where possible. If there is a reduction in cancer specific mortality that does not result in death from other sources or from misclassification, then this reduction should be reflected in a fall in overall cancer mortality (which includes cancer specific mortality). Because the base rate of overall cancer mortality is lower than that of overall mortality, tests have a higher power to detect such a difference. Overall cancer mortality can control for systematic errors in classifying cancer causes of death. ${ }^{3}$ It cannot, however, capture non-cancer deaths caused by treatment, which is a limitation.

\section{Tools for informed choice}

Prasad and colleagues write, "As long as we are unsure of the mortality benefits of screening, we cannot provide people with the information they need to make an informed choice. We must be honest about uncertainty." But even if this uncertainty cannot be removed, we can provide people with useful tools, such as fact boxes (figure ). ${ }^{6}$ We use a fact box on mammography screening that reports all three measures of mortality, based on a Cochrane review. ${ }^{7}$ It clearly shows that cancer specific mortality is reduced by 1 in 1000 women and that this difference is not reflected in overall cancer deaths nor in overall mortality. The harms are specified numerically so that an informed decision about screening is possible. Every article and pamphlet should provide a fact box summary to facilitate informed decisions.

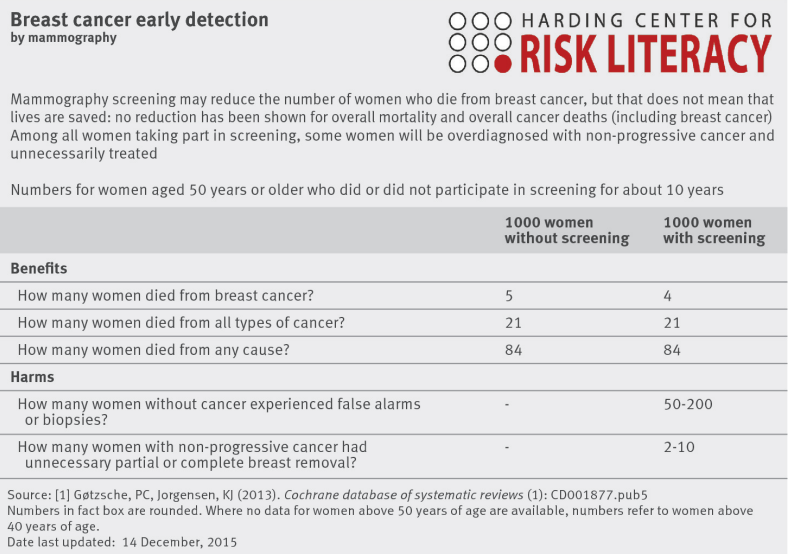

Fact box on mammography screening for breast cancer 
Rather than pouring resources into "megatrials" with a small chance of detecting a minimal overall mortality reduction, at the additional cost of harming large numbers of patients, we should invest in transparent information in the first place. It is time to change communication about cancer screening from dodgy persuasion into something straightforward.

Competing interest statement: I have read and understood BMJ policy on declaration of interests and have no relevant interests to declare.

Provenance and peer review: Commissioned; not externally peer reviewed
Gigerenzer G. Breast cancer screening pamphlets mislead women. BMJ 2014;348:g2636 Welch HG, Schwartz LM, Woloshin, S. Are increasing 5-year survival rates evidence of success against cancer? JAMA 2000;283:2975-8.

3 Prasad V, Lenzer J, Newman DH. Why cancer-screening tests have never been show to "save lives"-and what we can do about it. BMJ 2016;352:h6080.

4 Black WC, Haggstrom DA, Welch HG. Response: all-cause mortality in randomized trials of cancer screening. J Natl Cancer Inst 2002;94:865-6.

5 Wegwarth O, Schwartz LM, Woloshin S, Gaissmaier W, Gigerenzer G. Do physicians understand cancer screening statistics? A national survey of primary care physicians.
uns understand cancer screening statistics? A national survey of primary care physicians. Ann Intern Med 2012;156:340-9.

6 Schwartz LM, Woloshin S, Welch HG. Using a drug facts box to communicate drug benefits and harms: two randomized trials. Ann Intern Med 2009;150:516-27.

7 Gøtzsche PC, Jorgensen KJ. Screening for breast cancer with mammography. Cochrane Database Syst Rev 2013;6:CD001877.

Cite this as: BMJ 2016;352:h6967

(c) BMJ Publishing Group Ltd 2016 